\title{
Notas sobre la idea de un derecho a la educación: desde la filosofía política al Chile actual
}

Este artículo se encuentra disponible para su descarga gratuita en www.anuariocdh.uchile.cl

\begin{abstract}
Carlos Ruiz Schneider
Licenciado en Filosofía, Universidad de Chile. Doctor en Filosofía, Université Paris 8, Francia. Profesor titular, Departamento de Filosofía, Facultad de Filosofía y Humanidades, Universidad de Chile.

cruizsch@gmail.com
\end{abstract}

\section{RESUMEN}

Este artículo analiza la idea de un derecho a la educación, en particular, apuntando a determinar en qué medida este derecho se relaciona con el valor de lo público, y las consecuencias que de ello se derivan para pensar las políticas públicas en materia de educación en Chile hoy en día, tanto a nivel primario y secundario como universitario. Para ello, el autor realiza un recorrido por la filosofía política desde la Revolución Francesa hasta el siglo XX -desde Condorcet, pasando por Kant, Hegel y llegando a Michael Walzer-, rescatando una tradición de pensamiento que liga la educación con el valor de lo público y que les asigna a los ciudadanos un derecho a educarse, así como al Estado determinados deberes en esta materia. Desde esta perspectiva, se analiza el modelo educacional chileno implantado con la dictadura militar y vigente hasta hoy en día. Esto permite poner en cuestión ideas tales como el sistema de subvenciones escolares, así como reflexionar sobre la posibilidad de extender el derecho a una educación pública y gratuita a la educación superior.

Palabras clave: Derecho a la educación - Educación pública - Hegel - Chile-Subvenciones escolares - Universidad

\section{SUMMARY}

This article examines the idea of a right to education, particularly focused on determining to what extent the idea of a right to education is related to the idea of the public sphere, and the consequences that come from this relationship when thinking of educational public policies in today's Chile, at the primary, secondary and university levels. To this end, the author reviews political philosophy, from the French Revolution up to the twentieth century -from Condorcet, including Kant and Hegel and finishing with Michael Walzer- resuscitating a school of thought that ties education to the public sphere and which recognizes that citizens have a right to educate themselves and that the State has certain obligations in this field. The author then applies this perspective to analyze the Chilean educational system imposed by the military dictatorship and still in place today. This allows the author to question ideas such as the school vouchers system and to evaluate the possibility of extending the model of free public education to the university level.

Key words: Right to education - Public education - Hegel - Chile - School vouchers - University

\section{Introducción}

Uno de los debates importantes sobre educación y política en Chile se ha centrado en el tema de la educación pública. Algunos defensores del modelo educacional chileno, uno de los más privatizados del mundo, han sostenido que, en tanto productoras de bienes públicos, muchas instituciones de educación superior de propiedad de grupos privados tendrían que considerarse 
propiamente como instituciones públicas. De acuerdo con este argumento, el Estado no debiera discriminar a las instituciones privadas en sus aportes. Según alguna literatura reciente sobre el concepto económico de bien público, éste no parece ser un concepto demasiado adecuado para dirimir este tipo de discusiones, ya que aparentemente para algunos autores, de entre los bienes públicos producidos por las instituciones educacionales, solo la investigación científica podría cumplir en alguna medida con los requisitos de un bien público ${ }^{1}$.

El presente ensayo busca contribuir a estos debates sobre la educación pública, a partir del análisis de algunos textos filosóficos que relacionan más bien a la educación pública con la idea de un derecho a la educación, o con la idea de ciudadanía, democracia y justicia social, para concluir con un breve análisis crítico de algunos rasgos del sistema educacional chileno actual, tanto en el nivel primario y secundario como en lo relativo a la educación superior.

Partiré analizando un enfoque que podemos encontrar en los comienzos de la modernidad política, en la Revolución Francesa, para esbozar luego las ideas de lo público y el derecho a la educación en algunos filósofos post-revolucionarios como Kant y Hegel, y concluir con otros autores en el siglo XX. En un segundo momento, intentaré conectar esta reflexión con las relaciones entre lo público y la educación en Chile, comparando el modelo actual que pone énfasis en lo privado, con la defensa de lo público efectuada en la primera sección del artículo. Por último, se evalúa si esta idea de lo público en la educación que se refiere principalmente a la educación primaria y secundaria puede ser extendida a la educación universitaria ${ }^{2}$.

\section{El derecho a la educación en la filosofía política: un panorama desde la Revolución Francesa al siglo XX}

\subsection{El derecho a la educación para los pensadores de la Revolución Francesa}

La reflexión filosófica importante sobre los sistemas educacionales nacionales comienza con la Revolución Francesa. Es la República revolucionaria francesa -probablemente en la huella de Montesquieu y Rousseau, y con el aporte de filósofos que participan en la Revolución, como Condorcet- la primera en proponer que la educación es un tema fundamental del Estado y especialmente del Estado republicano. Este reconocimiento del papel central de la educación, le impone al Estado republicano la obligación de desarrollar la educación pública y desarrollarla asumiendo su papel de agente educacional fundamental.

Tiene, sin duda, el mayor interés analizar las concepciones y los debates educacionales de los intelectuales revolucionarios en Francia ${ }^{3}$. En uno de sus informes sobre educación pública Condorcet comienza por sostener que el primer fin de una instrucción nacional es ofrecer

1 Para Joseph Stiglitz, por ejemplo, "los bienes privados tienen las propiedades de consumo rival y de exclusión; los bienes públicos se caracterizan por el consumo no-rival [lo que significa que el consumo de una unidad más del bien, no tiene costos adicionales] y la imposibilidad de excluir a nadie de sus beneficios." STIGLITZ, Joseph. La economía del sector público. Barcelona: Antoni Bosch 2000, Cap. 6, p. 150. Según Stiglitz, entre los gastos del Estado, sólo la defensa nacional cumple con las exigencias definicionales de un bien público puro. Parece claro que, en general, el concepto de bien público difícilmente puede aplicarse a la educación, en general. Menos aún a la educación pagada suministrada por entidades privadas.

2 Para desarrollar esta reflexión me apoyaré de una manera importante en dos textos anteriores. El primero es una ponencia sobre "Hegel, la república y la revolución", presentada en el Seminario internacional sobre la Fenomenología del Espíritu Hegel realizado en la Universidad Diego Portales en el año 2007 y aún no publicado. El segundo texto es un ensayo titulado "Notas sobre el concepto de lo público y el 'modelo' educacional chileno" incluido en el libro de GUTIÉRREZ Claudia; MARTIN, Alan; RUIZ, Carlos y VERMEREN, Patrice (Comps.). Pasado y presente de la educación pública. Miradas desde Chile y Francia. Santiago: Catalonia, 2011.

3 En gran medida este trabajo analítico fundamental ha sido ya realizado en Francia, especialmente por autores como BACKZO, Bronislav, en su libro Une éducation pour la démocratie. Paris: Garnier, 1982, y por JULIA, Dominique en Les trois couleurs du tableau noir. La Révolution. Paris: Belin, 1981. 
a todos los individuos de la especie humana los medios de subvenir a sus necesidades, de asegurar su bienestar, de conocer y ejercer sus derechos, comprender y cumplir con sus deberes; asegurar a cada uno la facilidad de perfeccionar su industria, de hacerse capaz para las funciones sociales a las que tiene derecho a ser convocado, de desarrollar toda la extensión de los talentos que ha recibido de la naturaleza y, de esta suerte, establecer entre los ciudadanos una igualdad de hecho y hacer real la igualdad política reconocida por la ley ${ }^{4}$.

Para el filósofo, esta finalidad es "para el poder público, un deber de justicia" ${ }^{5}$. Este compromiso del poder público con la igualdad de hecho, que debe complementar la igualdad de derecho, lleva a Condorcet a proponer la gratuidad total de la enseñanza en todos sus niveles. Según Condorcet, la razón para esto es que es importante para

\begin{abstract}
la prosperidad pública dar a los niños de las clases pobres, que son las más numerosas, la posibilidad de desarrollar sus talentos; es un medio, no sólo de asegurar para la patria a más ciudadanos en estado de servirla, para las ciencias, más hombres capaces de contribuir a sus progresos, sino incluso de disminuir esa desigualdad que nace de la diferencia de las fortunas, mezclar entre ellas a las clases que tiende a separar esta diferencia ${ }^{6}$.
\end{abstract}

Condorcet no es, sin embargo, partidario de excluir otras visiones pedagógicas en escuelas privadas. Otros proyectos revolucionarios sobre instrucción pública mucho más radicales, como por ejemplo, el de Lepeletier de Saint Fargeau fusionan la obligación escolar, la universalidad y la gratuidad de la enseñanza con una política de internados para todos los niños y niñas entre los 6 y los 12 años, como la única manera de regenerar a la República y formar a los niños en la virtud política y los valores comunes. Con la derrota de los jacobinos radicales, triunfan en Francia visiones educacionales más liberales, como la del ideólogo Daunou que abandonan todas estas propuestas, en función de una educación laica, pero ni gratuita ni obligatoria.

La reflexión sobre lo público, el Estado y la educación, adquiere un nivel de profundidad notable en la Alemania post revolucionaria, especialmente en filósofos que pueden ser considerados filósofos de las transformaciones revolucionarias, como Kant y Hegel.

\title{
1.2 El pensamiento y lo público para Kant
}

Antecedentes de primera importancia para esta reflexión nos aporta la obra de Kant, que en una serie de textos políticos notables había ido desarrollando una concepción muy original y profunda sobre lo público, con repercusiones de gran hondura en la filosofía política contemporánea, especialmente en autores como Hannah Arendt y Jürgen Habermas.

Me parece que un aspecto especialmente significativo de la concepción kantiana sobre lo público tiene que ver con las exigencias que implica el momento de lo público para el desarrollo del pensamiento en general.

Como se sabe, Kant vincula estas exigencias con lo que Ilama "sentido común" en la Crítica del juicio y, en un sentido más amplio, con la Ilustración.

Contrariamente al entusiasmo romántico con la sola idea de la autenticidad en el ejercicio del pensar, Kant nos llama a compatibilizar nuestro pensamiento con las condiciones de lo que Ilama "sentido común". Entiende por esto

4 CONDORCET. "Informe y proyecto de decreto sobre la organización general de la instrucción pública presentado a la Asamblea Nacional, el 20 y el 21 de abril de 1792", citado en BACZKO, Bronislav. Une éducation pour la démocratie, op. cit., p. 181.

5 Ídem.

6 Ibídem, p. 201. 
la idea de un sentido que es común a todos, es decir, de un juicio que, en su reflexión, toma en cuenta, [...] el modo de representación de los demás para atener su juicio a la razón total humana, y, de este modo, evitar la ilusión que, teniendo su origen en condiciones privadas subjetivas, fácilmente podrían ser tomadas por objetivas y tendría una influencia perjudicial en el juicio ${ }^{7}$.

Según Kant, máximas que aclaran los principios del sentido común son: el pensar por sí mismo; en segundo lugar, el pensar en el lugar de cada otro y en tercer lugar, pensar siempre de acuerdo consigo mismo.

La primera "se refiere a la máxima del modo de pensar libre de prejuicios". Para Kant, lo contrario de los prejuicios es la Ilustración. En su escrito "Qué es la Ilustración", de 1784, sostiene que para ella "únicamente se requiere libertad y, por cierto, la menos perjudicial entre todas las que llevan ese nombre, a saber, la libertad de hacer siempre y en todo lugar uso público de la razón" ${ }^{8}$.

La segunda máxima tiene que ver con lo que Kant Ilama la amplitud en el modo de pensar, la que consiste en reflexionar "sobre su propio juicio desde un punto de vista universal (que solo puede ser determinado poniéndose en el punto de vista de los demás)" ${ }^{\prime}$.

La tercera máxima, por último, "se refiere al modo de pensar consecuente"10, lo que tiene que ver con la coherencia entre la teoría y la praxis.

Como es evidente en la misma formulación kantiana, estas máximas del sentido común implican un rigor especial en nuestro pensamiento, el que se relaciona profundamente con las exigencias del carácter público del mismo. Pensar en público significa para nosotros una exigencia de superación de nuestro particularismo y de los prejuicios ligados al uso exclusivamente personal e idiosincrático del pensar.

A pesar del enorme interés de esta reflexión sobre lo público para la educación, Kant no conecta ambos temas explícitamente, y, a pesar de que desarrolla argumentos importantes para justificar una preferencia de la educación pública sobre la privada y de que espera del desarrollo de la educación una mejora para la humanidad, no relaciona de una manera precisa al sentido común ni a la llustración con la educación.

\subsection{Hegel: la educación pensada como derecho del individuo y obligación de la sociedad}

En cambio, el punto de partida de la concepción de Hegel sobre la educación, como lo afirma Anne Sauvagnargues es, precisamente, considerarla como algo de esencial interés público, como un derecho, y como un derecho de todos los niños. Esta tesis de Hegel se funda, a su vez, en que la educación es un momento de la realización de la libertad del niño, no solo un factor de supervivencia, y en la consideración de que la determinación esencial del derecho es ser realización de la libertad ${ }^{11}$.

KANT, Immanuel. Crítica del juicio. Buenos Aires: Librería El Ateneo, 1951, p. 304.

8 KANT, Immanuel. “¿Qué es la Ilustración?” En: MAESTRE, Agapito (Ed.) ¿Qué es Ilustración? Madrid: Tecnos, 2002, p. 19.

9 Ibídem, p. 305

10 Ídem.

11 SAUVAGNARGUES, Anne. "L'éducation chez Hegel". En: KAHN, Pierre; OUZOULIAS, André et THIERRY, Patrick. L'éducation: approches philosophiques. Paris: PUF, 1990, p. 248. En relación a la útil distinción de Amy Gutmann, entre concepciones educacionales centradas en la felicidad y la libertad, la concepción de Hegel se inserta en las teorías educacionales que tienen como su concepto básico el de libertad. De aquí su proximidad con la idea de derecho a la educación. Ver GUTMANN, Amy. "What's the use of going to school? The problem of education in utilitarianism and 
Y esto es así, a su vez, para Hegel, porque el hombre, a diferencia del animal, "no es, por naturaleza, todo lo que debe ser [...] Lo que el hombre debe ser [...] debe adquirirlo, y es en esto que se funda el derecho de los niños a ser educados"12. Este derecho de los niños implica una obligación de la sociedad.

Ahora bien, para nuestro autor, la educación es una instancia de mediación, que se sitúa entre la existencia inmediata del niño en la familia y el mundo del trabajo y la política, esto es del mundo público de la sociedad y el Estado. Es importante subrayar, en este sentido, que el concepto de lo público en Hegel es más amplio que el de Kant, pues incluye no sólo la esfera política, sino también el trabajo.

"La escuela se encuentra -nos dice Hegel en su Discurso del Gimnasio de Nüremberg- entre la familia y el mundo real y constituye el miembro intermedio, conector en el tránsito desde aquella a éste ${ }^{\prime 13}$. En este mismo texto, nos dice Hegel que

[...] la vida en la familia, que antecede a la vida en la escuela, es una relación personal, una relación del sentimiento, del amor, de la fe y la confianza naturales [...] el niño posee aquí un valor porque él es el niño; experimenta, sin mérito suyo, el amor de sus padres, así como tiene que soportar su enojo, sin tener derecho a oponerse. Por el contrario, en el mundo, el hombre vale mediante lo que hace; sólo posee valor en la medida en que lo merece. Pocas cosas le ocurren por amor y a causa del amor; aquí vale la cosa, no el sentimiento ni el sentimiento particular. El mundo constituye un ser común, independiente de lo subjetivo; el hombre vale ahí según las habilidades y la aptitud para una de sus esferas, cuanto más se haya despojado de la particularidad y se haya formado en el sentido de un ser $y$ un obrar universales ${ }^{14}$.

En la escuela -prosigue Hegel en este sentido- "callan los intereses privados y las pasiones egoístas [...] Pero si la vida de la escuela es más desapasionada, también se halla privada a la vez del interés superior y de la seriedad de la vida pública; la escuela consiste tan sólo en una preparación y en un entrenamiento silenciosos, interiores, para la misma"15.

Ahora bien, Hegel trata más sistemáticamente, pero también más brevemente, de la educación en la Filosofía del Derecho. En el parágrafo 239 de dicha obra, Hegel aborda de nuevo esta relación entre la educación, lo privado y lo público. Y sostiene aquí que

[...] la sociedad civil tiene, frente al arbitrio y la contingencia de los padres la obligación y el derecho de ejercer control e influencia sobre la educación, en la medida en que ésta se refiere a la capacidad para devenir miembro de la sociedad [...] Es igualmente un deber y un derecho de la sociedad erigir instituciones comunes para esos fines siempre que sea posible ${ }^{16}$.

En el agregado al parágrafo dice Hegel que "Los padres suponen corrientemente que respecto a la educación tienen total libertad y pueden hacer todo lo que quieren. La principal oposición contra toda medida que haga pública la enseñanza suele provenir de los padres, que se quejan contra maestros e instituciones porque su voluntad particular los enfrenta a ellos". A pesar de esto, piensa que "la sociedad tiene derecho a actuar según sus probadas opiniones y obligar a los padres

rights theories". En: SEN, Amartya and WILLIAMS, Bernard (Eds.). Utilitarianism and beyond. Cambridge: Cambridge University Press - Éditions de la Maison des Sciences de I'Homme, 1982.

12 HEGEL, G.W. F. Filosofía del Derecho. Barcelona: EDHASA, 1988, par. 174, p. 250.

13 HEGEL, G.W.F. "Discurso del Gimnasio de Nüremberg del 2 de septiembre de 1811". En: Escritos Pedagógicos. México: Fondo de Cultura Económica, 1998, p. 105.

14 Ídem.

15 Ibídem, p. 108.

16 HEGEL, G.W. F. Filosofía del Derecho, op. cit., par. 239, p. 306. 
a mandar a sus hijos a ir a la escuela, hacerlos vacunar contra la viruela etc." ${ }^{17}$. Hegel conecta esto explícitamente en su texto con las disputas que tienen lugar en Francia entre la libertad de enseñanza y el control del Estado. Es por esto, piensa el filósofo, que el Estado debe intervenir en la educación construyendo instituciones de educación pública que hagan realidad el derecho de los niños a educarse, es decir que la educación debe ser "un apoyo para el sentimiento de sí que se despierta, es decir una formación en vistas de la independencia"18.

En un sentido paralelo, puede decirse que es la dialéctica propia del concepto de libertad en Hegel, en un segundo momento de diferenciación que supera el carácter puramente negativo de la libertad en su primera forma abstracta, y que exige que optemos por ser algo en la vida, que tengamos una ocupación y un trabajo socialmente reconocidos, y que participemos de la vida común en el Estado como ciudadanos, la que está detrás de la obligación del Estado de apoyar este camino de libertad del niño, a través de la educación, como un proceso que requiere instituciones públicas y que puede requerir la obligación escolar. Libertad y reconocimiento se unen, pues, en la concepción hegeliana de la educación. El tema del reconocimiento es importante, porque en la concepción de Hegel, la relación de trabajo, además de relacionarnos con las necesidades y la sobrevivencia, es también un lugar central para la afirmación de la autoestima, precisamente a través del ser reconocidos.

Para cerrar este breve análisis del concepto de educación en Hegel, me parece conveniente recordar la reflexión del autor sobre el concepto de cultura, a la que concibe como un proceso de liberación que nos permite pensar esta idea de derecho a la educación en un contexto más profundo.

Parte Hegel en el parágrafo 187 de la sección sobre la sociedad civil, por recordarnos que como miembros de ésta, los individuos son personas privadas que tiene por fin su propio interés, el que debe ser mediado por lo universal, que tiene que determinar su actuar, para que nos encontremos con las demandas del otro. Este proceso, por el que la subjetividad se cultiva en su particularidad, es, según Hegel, en general la cultura en su significación ética y filosófica.

Sostiene Hegel que "la cultura es por lo tanto la liberación y el trabajo de liberación superior, el punto de tránsito absoluto [...] a [...] la eticidad, que ya no es más inmediata, natural, sino espiritual y elevada a la figura de la universalidad. Esta liberación es en el sujeto el duro trabajo contra la mera subjetividad de la conducta, contra la inmediatez del deseo, así como contra la vanidad subjetiva del sentimiento y la arbitrariedad del gusto"19. Es pues este significado liberador de la cultura -en el que pueden percibirse ecos de las exigencias contenidas en la idea kantiana de lo público-, lo que funda en último término en Hegel la necesidad de la educación.

Como dice Anne Sauvagnargues comentando las ideas educacionales de Hegel, no hay ninguna duda que es el Estado el que puede garantizar este paso del niño a una nueva dimensión, la del mundo público:

Hacer la experiencia de la realidad, formarse en el sentido de un ser y de un actuar universales consiste en hacer el aprendizaje de las relaciones con el mundo público. Esta experiencia pública exige el recurso del Estado, que arranca al niño de la esfera familiar para introducirlo en la dimensión objetiva de la cultura y de la ética. La educación privada encuentra aquí su límite necesario. Porque sólo el Estado puede, en nombre de la sociedad entera, tomar en sus manos el destino individual al interior de una institución pública, es decir, a la vez objetiva e igualitaria ${ }^{20}$.

17 Ídem.

18 Ibídem, p. 109.

19 Ibídem, p. 265.

20 SAUVAGNARGUES, Anne. "L'éducation chez Hegel", op. cit., p. 253. 
En la sociedad moderna, solo el Estado puede y debe responder, en la concepción de Hegel, con la obligación de proveer educación, al derecho del niño a la educación, el que está enraizado profundamente en su libertad y en su camino hacia la esfera política, hacia la ciudadanía. Para nuestro autor es claro que la sociedad civil y el mercado no pueden garantizar derechos inclusivos, como el derecho a la educación, sin contradecir su lógica más profunda, que es la de considerar a las personas como individuos privados con su capital, sus talentos y habilidades y reconocerlos por su eventual satisfacción de las demandas y preferencias de los demás.

Según Hegel, en principio, no hay límites a este derecho a la educación, que tiene que ver con la preparación y la formación que hace de cada uno de nosotros alguien reconocido en el mundo y un ciudadano, aunque la duración y el carácter de los estudios y su éxito tengan que estar también determinados por el interés y la capacidad personales.

Una última consideración que es necesario realizar se relaciona con la vinculación que es necesario trazar entre la educación en Hegel y su idea del Estado.

En efecto, Hegel trata de la educación en la sección de la "sociedad civil" sobre "el poder de policía" y no en la sección de su obra sistemática sobre el Estado. Me parece que esto se debe a que no le parece suficiente considerar a la educación, en sentido estricto, solo como un derecho. Y esto, porque para Hegel, el concepto de derecho, incluso si, como él piensa, se relaciona con una idea de obligación correlativa, es inadecuado para pensar los bienes de bienestar, como la educación.

El Estado hegeliano apunta, en efecto, más allá del estado liberal, más allá de la protección neutral de los derechos de los individuos y de una garantía de los derechos recíprocos. No basta, para Hegel, con que se proteja a la persona a través de la administración de justicia y la garantía de los derechos. Se necesita ir más allá para asegurar la "subsistencia y el bienestar del individuo" y -paradójicamente- para que "el bienestar particular sea tratado como derecho y realizado" ${ }^{21}$. Este espacio más allá del derecho es el poder de policía y, en cierto sentido, también, el Estado.

El Estado moderno es precisamente ese tipo de institucionalidad que realiza de la manera más desarrollada la libertad concreta como unidad de universalidad y abstracción y particularización. El agregado del parágrafo 260, dice en este sentido que

\begin{abstract}
La esencia del nuevo Estado es que lo universal está unido con la completa libertad de la particularidad y con la prosperidad de los individuos, que el interés de la familia y la sociedad civil debe concentrarse, por lo tanto, en el Estado y que la universalidad del fin no debe progresar [...] sin el saber y el querer propio de la particularidad que tiene que conservar su derecho. Lo universal tiene, pues, que ser activo, pero por otro lado la subjetividad debe desarrollarse en forma completa y viviente. Sólo si ambos momentos se afirman en su fuerza, puede considerarse que el Estado está articulado y verdaderamente organizado ${ }^{22}$.
\end{abstract}

Es, por último, en este sentido que Hegel considera que el Estado moderno significa también una ampliación del modelo del Estado republicano, centrado en la virtud, que surge del jacobinismo de la Revolución Francesa: "en un grado más evolucionado de la sociedad y ante el desarrollo y liberación de las fuerzas de la particularidad, la virtud de quienes dirigen el Estado resulta una condición insuficiente. Se requiere otra forma de ley racional, que vaya más allá de la disposición de ánimo, para que el todo tenga la fuerza de mantenerse unido y acordar a las fuerzas de la particularidad desarrollada su derecho, tanto negativo como positivo" 23 .

21 HEGEL, G.W. F. Filosofía del Derecho, op. cit., par. 239, p. 302.

22 Ibídem, par. 260.

23 Ibídem, par. 273, p. 356. 
La reflexión crítica, durante el siglo XIX, en general abandona esta concepción de Hegel que conecta a la educación con un proceso de liberación y con el Estado. Para Marx, por ejemplo, la educación en la sociedad de clases es un instrumento de opresión y en la sociedad del futuro, probablemente no será el Estado quien la coordine y dirija.

\subsection{El derecho a la educación en la filosofía política del siglo XX: desafiando las lógicas económicas}

Durante el siglo XX tampoco son frecuentes las concepciones de la educación que la piensen en términos de un derecho de bienestar que debe ser garantizado por el Estado. Para John Dewey, por ejemplo, que ya no piensa la educación a partir de premisas republicanas, sino a partir de sus particulares concepciones del liberalismo y la democracia, la referencia al Estado implica el peligro de subordinar la educación a los intereses nacionales ${ }^{24}$.

La obra de T.H. Marshall expresa la revitalización de los derechos económicos y sociales, entre los que se ubica el derecho a la educación, en los Estados de bienestar de la posguerra ${ }^{25}$. Pero esta revitalización es algo ambigua, ya que de alguna manera los derechos sociales tienen que articularse con las teorías del desarrollo económico, los que terminan por darle prioridad a una conceptualidad fundamentalmente económica. Un ejemplo de este reduccionismo de las ideas sobre la educación es el concepto de "capital humano" que pronto estará a la base de una visión de la educación que la conecta esencialmente con el mercado.

Si revisamos, más avanzado el siglo XX, las teorías contemporáneas de la justicia y la educación, nos encontramos, sin embargo, con puntos de vista similares a los de Hegel, especialmente en la obra de Michael Walzer, cuyo trabajo presenta para nosotros el interés de contener críticas a uno de los intentos más radicales de fundamentar las políticas educacionales en el mercado: la idea de los vouchers o subvenciones a la demanda en educación, propuesta por uno de los defensores del mercado en educación, el economista Milton Friedman.

En Esferas de la Justicia, por ejemplo, Michael Walter sostiene que las escuelas "Ilenan un espacio intermedio entre la familia y la sociedad y, también, un tiempo intermedio entre la infancia y la edad adulta" ${ }^{26}$. Según Walzer, la educación

se define [...] mejor [...] como la preparación de individuos específicos, con identidades, aspiraciones y vidas propias. Esta particularidad es representada por la familia y defendida por los padres. Las escuelas autónomas son instituciones mediadoras, y mantienen una relación de tensión con los padres (pero no sólo con ellos). Al derogar la educación obligatoria se pierde la tensión; los niños se convierten en meros objetos de sus familias y de la jerarquía social en donde sus familias están inmersas. Al derogar a la familia la tensión se perderá también, y los niños se convertirán en meros objetos del Estado ${ }^{27}$.

Los vales educativos le parecen a Walzer una propuesta del primer tipo:

El plan se orienta -nos dice- a la creación de una sociedad donde no existiría ninguna base geográfica sólida, ni una lealtad basada en las costumbres, sino más bien una considerable variedad de grupos ideológicos -o mejor dicho de grupos de consumidores reunidos por el mercado-. Los ciudadanos serían altamente móviles, desarraigados, y transitarían con facilidad de una asociación a otra. Sus movimientos equivaldrían a sus elecciones, de modo que evitarían las interminables discusiones y concesiones de la actividad política democrática, cuyos participantes están más o menos permanentemente compenetrados

24 DEWEY, John. Democracy and education. New York: The Free Press: 1966, p. 93.

25 MARSHALL, Thomas H. Ciudadanía y clase social. Madrid: Alianza, 1998 (1ª edición: 1950).

26 WALZER, Michael. Esferas de la justicia. México: Fondo de Cultura Económica, 1993 (1ª edición: 1983), p. 209.

27 Ibídem, p. 227. 
entre sí. Los ciudadanos en posesión de vales podrían elegir siempre, en la terminología de Albert Hirschman, la "salida" en vez de la "voz"28.

Para la mayoría de los niños, dice Walzer, "la elección de los padres significa menos diversidad, menos tensión, menos oportunidad para cambios personales que lo que encontrarían en escuelas a las que fueran políticamente asignados. Las escuelas serían más como sus casas. La etnicidad y la raza serían seguramente, como lo son hoy (en los Estados Unidos), dos de los principios en torno a los cuales se organizarían las escuelas privadas" 29 .

Pero la comunidad, sostiene el filósofo estadounidense,

tiene interés en la educación de los niños y también lo tienen los niños que no están representados ni por sus padres ni por los empresarios. Pero ese interés debe ser debatido públicamente y se le debe dar una forma específica. Tal es la tarea de asambleas, partidos, movimientos y clubes democráticos. Y es el patrón de asociación necesario para este trabajo el que debe ser anticipado por la educación básica. Las escuelas privadas no hacen eso. La provisión común de bienes educacionales [...] tiene que asumir una forma más pública, si no, no contribuirá a la formación de ciudadanos ${ }^{30}$.

Walzer no cree que esto signifique un ataque a la opción de los padres ya que su función es proveer diversidad en los márgenes del sistema público. En principio, sostiene, "los bienes educacionales no debieran ser aptos para la venta, pero la venta es tolerable si no lleva consigo (como hoy por ejemplo, en Inglaterra) enormes ventajas sociales. Aquí, como en otras áreas de provisión común, mientras más fuerte es el sistema público, menos inquietos podemos estar por el uso del dinero fuera de sus límites" ${ }^{\prime \prime}$.

Vemos así también cómo, desde una visión filosófica como la de Walzer, la relación predominante o exclusiva entre educación y mercado es altamente problemática para lo que constituye uno de los fines principales de la educación en una República democrática: su contribución a la formación de ciudadanos, o más en general, su contribución a la constitución de una comunidad política crecientemente igualitaria. No tenemos que terminar, sin duda, con la educación privada. Pero la única manera en que ella contribuya menos a la reproducción de la desigualdad social, es fortalecer la educación pública en todos sus niveles, asegurando el rigor de su producción intelectual, democratizando sus estructuras internas y favoreciendo el más amplio pluralismo.

\section{Las políticas educacionales en Chile desde 1973}

Con esta primera aproximación filosófica en la memoria, revisemos ahora brevemente algunos rasgos de las políticas educacionales en Chile en los últimos años.

Difícilmente podríamos encontrar en el mundo una concepción educacional más alejada de las perspectivas teóricas y normativas que acabamos de sintetizar y que tuvieron en Chile mucha vigencia hasta el año 1973.

Desde 1979 en adelante, se impone en Chile por decretos de la dictadura militar, una política de privatización casi total del espacio de la escuela y del sistema educacional en su conjunto, el que continúa en sus grandes líneas -a través de leyes de quórum calificado como la Ley Orgánica Constitucional de Educación, de 1990 y la Ley General de Educación del año 2007- hasta hoy.

\footnotetext{
28 Ibídem, p. 229.

29 Ídem.

30 Ibídem, p. 219.

31 Ídem.
} 
¿Cuáles son los hitos fundamentales de este modelo que todos conocemos? Primero, hay que subrayar que el grado de privatización de la educación chilena es uno de los más elevados del mundo. Según datos contenidos en el Informe de la OCDE del año 2004, el 47\% de la educación básica y media del país es administrada privadamente. En cuanto a la educación superior, el 70\% corresponde a gasto privado, a cargo de las familias ${ }^{32}$.

Esto es un resultado de que en estos años, la agencia fundamental de la educación se traslada del Estado a los individuos, sus familias y el mercado. El Estado y las políticas públicas en educación pasan a ser concebidas a partir del principio de la subsidiariedad, lo que significa que el sistema público solo debe intervenir en esta esfera cuando los agentes privados son incapaces de responder a las demandas de las personas, esto es, cuando se trata de la educación de los sectores más pobres.

Ahora bien, el gasto del Estado en educación se divide entre el financiamiento de una educación propiamente estatal, que pasará a estar a cargo de las Municipalidades y que está orientada hacia los grupos de bajos ingresos, que por esta razón no pueden comprar bienes educacionales en el mercado, y el financiamiento a través de subvenciones (o vouchers, según la propuesta de Milton Friedman) a instituciones privadas de educación que administran esos fondos estatales privadamente, y cuyos servicios son, en principio, gratuitos, aunque en los últimos años se aceptó también una modalidad de financiamiento compartido para las familias que poseen más recursos.

El fundamento teórico para este gasto estatal se basa estrictamente en su rentabilidad. En efecto, desde las primeras propuestas educacionales de Pinochet, nos encontramos con la idea de que solo la educación primaria gratuita se justifica y que la educación secundaria y universitaria constituyen situaciones de privilegio -lo que se opone término a término a la idea de un derecho social a la educación- por las que los usuarios deben pagar. Con posterioridad a estas primeras políticas, se aceptará también ir incluyendo progresivamente a la educación secundaria en el mismo marco normativo de la educación básica.

Subrayo estos puntos para hacer ver que el modelo educacional de Pinochet, que es básicamente el que rige hasta hoy día, basado en la libertad de emprender en educación y en una concepción de la educación como bien de consumo que hay que adquirir a su costo en el mercado, se opone radicalmente a la idea de un derecho republicano a la educación como el que encontrábamos, por ejemplo, en los autores que revisamos más arriba.

En realidad, esta lógica privatizadora no solo se opone radicalmente a la idea de un derecho de los ciudadanos la educación, sino que en base al principio de subsidiariedad, a los cálculos de utilidad de los agentes supuestamente libres y racionales y a la libertad de escoger, solo concibe un lugar para la educación pública estatal en relación a "los que sobran", para los que están en los márgenes del sistema, donde habitan los pobres, esos agentes escasamente racionales, poco libres en sus vidas y malos para el cálculo de utilidades. Esta educación para pobres ni necesita, ni puede ser demasiado buena. No puede serlo porque eso desincentivaría el emprendimiento de los agentes racionales que maximizan utilidades tratando a la educación como un bien de consumo igual a los otros y vendiéndola en el mercado.

\section{La educación subvencionada desde una mirada de lo público en la educación}

Hay un conjunto importante de evaluaciones disponibles sobre lo que ha significado este modelo, en especial la educación subvencionada. Muchas de ellas subrayan que, a pesar de que el gasto

32 Organización para la Cooperación y el Desarrollo Económico (OCDE). Chile. Revisión de las políticas nacionales de educación. París: OCDE, 2004. 
en las subvenciones es estatal, el efecto de la educación subvencionada no tiene que ver con introducir a los alumnos propiamente en un mundo público y plural, como se necesita, por ejemplo, en la concepción de Michael Walzer, para ir preparando una convivencia entre futuros ciudadanos, sino que los aísla y separa, manteniéndolos más bien apegados a la clase social y a los símbolos y valores de sus familias.

Una de estas evaluaciones, que se refiere específicamente a los efectos de la subvención educacional hasta el año 2000, es la contenida en un ensayo de dos investigadores norteamericanos, Chang Tai Hsieh de la Universidad de Princeton y Miguel Urquiola de la Universidad de Cornell ${ }^{33}$. En su estudio, los investigadores someten a una evaluación las políticas de subvenciones a la educación en Chile durante los 20 años que van desde su implementación. Sus conclusiones son demoledoras. "No existen evidencias", sostienen, "que el traspaso de estudiantes de colegios públicos a privados -que fue uno de los efectos, durante un cierto período, de las políticas de subvención, y que dejaron en el sistema municipalizado a los escolares de situación económica más precaria- haya mejorado el rendimiento educacional promedio en Chile" ${ }^{\prime 34}$. La competencia entre la educación municipalizada y la subvencionada se planteó, sobre todo, en términos de quién atraía a los niños de más altos ingresos. Dicen los investigadores, "los colegios particulares subvencionados han buscado estudiantes dándose a sí mismos ciertos símbolos asociados previamente con la élite (colegios privados), como uniformes o el uso de nombres extranjeros, particularmente ingleses" 35 . Pero esto no ha significado ningún mejoramiento de la calidad de la enseñanza en Chile en los últimos 20 años. A pesar de que los colegios subvencionados, debido al traslado de niños con más capital cultural, han logrado mejores resultados que los colegios públicos en mediciones internacionales, los colegios públicos tienen mejores resultados en el segmento de niños con situación socioeconómica más desmedrada. Y el nivel general de la enseñanza en Chile, según estos concursos internacionales como el TIMSS ha decaído, en lugar de mejorar.

Una segunda evaluación interesante es la contenida en el informe de la OCDE mencionada más arriba. El documento contiene un diagnóstico muy crítico de estos modelos privatizadores en educación y en particular, sobre las subvenciones. En el capítulo final sobre "Conclusiones y recomendaciones" el informe dice: "La educación chilena está influenciada por una ideología que da una importancia indebida a los mecanismos de mercado para mejorar la enseñanza y el aprendizaje $\mathrm{e}^{\prime 36}$.

Por su parte, Juan Pablo Valenzuela en un ensayo del año 2008, que recoge una investigación sobre educación y desigualdad sostiene que:

\begin{abstract}
Los resultados previos informan de una alta segregación socioeconómica entre los estudiantes chilenos. En términos internacionales y en una comparación entre 57 países, el sistema escolar chileno presentaba en 2006, junto a Tailandia, las situaciones más extremas de segregación, tanto para los estudiantes de menor Nivel Socio Económico como entre los estudiantes de mayor NSE. Asimismo, los antecedentes nacionales permiten indicar que el grado de segregación por NSE ha sido creciente entre 1999 y 2006, lo que conlleva un intenso proceso de "aislamiento" o estratificación de los estudiantes en las escuelas de acuerdo a las condiciones sociales y económicas de las familias.
\end{abstract}

\footnotetext{
33 TAI HSIEH, Chang and URQUIOLA, Miguel. "When schools compete, how they compete? An assessment of Chile's nationwide voucher program". Occasional Paper No. 43. New York: National Center for the Study of Privatization, 2002.

34 Ídem.

35 Ídem.

36 OCDE. Chile. Revisión de las políticas Nacionales de Educación, op. cit., p. 290.
} 
Recientes investigaciones indican que [...] principalmente son factores institucionales del sistema escolar chileno los que profundizan este proceso, en particular la posibilidad de cobrar a los padres por la educación pública ${ }^{37}$.

En general, podríamos decir -en base a estos y otros estudios empíricos- que las políticas educacionales privatizadoras en Chile, desde 1978 hasta la fecha, a pesar del importante -pero no muy sorprendente- aumento en cobertura desde 1990 hasta hoy, especialmente en educación superior, no solo han mantenido, sino que han aumentado sensiblemente la desigualdad entre los estudiantes, acercando cada vez más la escuela a la clase social. Esta era la razón profunda por la que, en su época, autores como Hegel o Condorcet $-y$ muchos otros- subrayaban la necesidad de un derecho de bienestar a la educación -o relacionaban a la educación con la democracia y la justicia-, como en los casos de Dewey y Walzer: la educación es un momento fundamental en la constitución de los sujetos libres e iguales que exige una concepción moderna de la ciudadanía. No educamos a esos ciudadanos iguales y socialmente reconocidos que necesita nuestra democracia en instituciones que, precisamente, reproducen o hasta aumentan las enormes desigualdades introducidas en Chile por la economía de mercado plena, y que segregan y diferencian socialmente a sus estudiantes aún más, incluso, que lo que lo hacen sus barrios.

\section{La educación y lo público: significación para las universidades}

Para terminar, sólo diré que no me parece tan claro que podamos simplemente generalizar las consideraciones que hemos realizado hasta ahora al campo de la educación universitaria. Y esto porque la destrucción de la educación estatal en el campo de las universidades, a pesar de todos los intentos por hacerlo (el más recordado es el José Luis Federici, que después de desmantelar los Ferrocarriles del Estado, trató de hacer lo propio con la Universidad de Chile), no ha tenido el mismo nivel de profundidad que en la educación primaria y secundaria.

La educación universitaria estatal, a pesar del escaso aporte económico del Estado que bordea el $10 \%$ del total -cuando los estudios del Banco Mundial recomendaban tímidamente a fines de los 1990 bajar el aporte estatal al 65\%-, continúa siendo en Chile relativamente fuerte, con los más altos índices de producción científica y elegida por los mejores estudiantes.

Pero es claro que la situación tiende a revertirse cada vez más, precisamente por este magro aporte estatal, que tiende a repercutir, sobre todo, en las Facultades sin un componente tecnológico o de otro tipo, que permita que los conocimientos producidos sean de interés para las empresas.

En segundo lugar, diría que el sistema escolar es precisamente un sistema y que las desigualdades educacionales en el sistema universitario -estatal o no- tienen su punto de origen en la desigualdad social en Chile y en la forma como, primero la sociedad de mercado y luego la escuela, mantienen y reproducen estas desigualdades antes del ingreso a la Universidad.

Pero también aquí, como en el caso del sistema escolar en general, la extensión de la privatización -que es difícilmente compatible con un sistema estatal fuerte y de calidad que tendería a marginalizar al sistema privado-, amenaza el derecho a la educación, la justicia y la igualdad educacionales y el desarrollo de un espacio público crítico y plural.

La pregunta que habría que hacerse es, entonces: ¿garantiza en las actuales condiciones la educación superior pública y estatal chilena, algo así como un derecho a la educación?

37 VALENZUELA, Juan Pablo. "Segregación en el sistema escolar chileno: en la búsqueda de una educación de calidad en un contexto de extrema desigualdad". En: Transformaciones del Espacio Público. II Escuela Chile Francia. Santiago: Universidad de Chile y Embajada de Francia, 2008, p. 152. 
Como lo dice Fernando Atria en un excelente artículo, "la educación pública es la que está sometida a un régimen legal conforme al cual ella está, en principio, abierta a todos como ciudadanos". A lo que agrega "sólo ante los establecimientos del Estado, el individuo concurre como ciudadano que ejerce un derecho" ${ }^{\prime 38}$.

En su análisis -que concuerda, en base al caso chileno, con las ideas que revisamos al comenzar este ensayo- la educación pública está abierta a todos los ciudadanos y está ligada esencialmente a un derecho a la educación y a la gratuidad de este tipo de enseñanza. Aunque su estudio se refiere a la educación básica y secundaria, me parece que podríamos generalizar esta conclusión también para el tramo superior.

Sobre este punto habría que decir, en primer lugar, que desde la Ley de 1879, que dio forma a la enseñanza universitaria estatal en Chile, este derecho sí se garantizó a nivel legal, precisamente a través de la gratuidad de la educación universitaria. Esta situación persiste hasta 1979, cuando, con la dictadura militar, se impone autoritariamente el modelo de mercado, que hace de la educación un bien de consumo por el que se debe pagar.

En base a estas razones habría que contestar que las universidades públicas chilenas actuales, enmarcadas en los decretos de la dictadura y, a pesar de sus reformas posteriores, no garantizan este derecho.

Puede discutirse si todos los estudiantes que terminaron la escuela secundaria tienen un derecho incondicional -como lo tienen a la educación en general- a la educación superior, y en qué sentido o dentro de qué límites el derecho general a la educación es aplicable al caso de la educación superior. Las sociedades democráticas responden esta pregunta de maneras distintas y de acuerdo a principios morales y constitucionales diferentes. Algunas instalan mecanismos básicos de selección y otras no lo hacen. Lo que parece claro, en todo caso, es que probablemente solo mecanismos de selección basados en el interés por la disciplinas y en las capacidades de los estudiantes pueden justificarse como límites, y no puede justificarse, en una sociedad republicana y democrática, ningún criterio de selección que se base en la capacidad de pago o de endeudamiento de los estudiantes o sus familias.

Pero aun esto es muy problemático, porque sabemos que el rendimiento de los estudiantes en las pruebas de selección está fuertemente condicionado por la clase social y el nivel socioeconómico de las familias de origen. Ahora bien, como lo indican muchos filósofos políticos contemporáneos, como John Rawls, seleccionar a los estudiantes en base a estas características, que no constituyen mérito personal alguno, violaría claramente los principios de la justicia, aunque podría ser más eficiente, en términos del uso de las finanzas públicas. Como en Rawls, sin embargo, la eficiencia está claramente subordinada éticamente a la justicia, porque los criterios de eficiencia precisamente no garantizan contra violaciones de derechos fundamentales, no pueden justificarse políticas públicas que tengan por base solo la eficiencia en el uso de los recursos.

En base a estas razones, entonces, uno podría concluir que si queremos construir un sistema de educación superior que garantice, aun con sus límites específicos, el derecho a la educación, o un acceso a la educación que sea justo e igualitario, este sistema tendría que ser también fundamentalmente gratuito.

38 ATRIA, Fernando. “¿Qué educación es pública?” En: BELLEI, Cristián; CONTRERAS, Daniel y VALENZUELA, Daniel (Eds.). Ecos de la revolución pingüina. Avances, debates y silencios en la reforma educacional. Santiago: Universidad de Chile-UNICEF, 2010. 